\title{
SPECTROSCOPY IN THE METALLURGICAL INDUSTRY
}

T HE trend towards more automatic methods for production control analysis was shown at a recent symposium held at Buxton, Derbyshire, arranged by the Spectroseopy Group of the Institute of Physics and the Physical Society in collaboration with the British Iron and Steel Research Association and the British Non-Ferrous Metals Research Association. An audience of about 130, including some overseas visitors, heard a range of eight papers in three half-day sessions (July 5-6) covering X-ray, optica] and mass spectroscopic methods.

Analytical procedures depending on X-ray fluorescence are based on the simple and characteristic radiation emitted when X-rays fall on an element while those relying on optical spectroscopy involve the line spectra emitted when the element is excited by an electrical discharge. Mass spectroscopic methods involve measurement of the mass of the ion produced from similar discharges. All three methods have contributed to the knowledge of the electronic configuration of atoms, but it is only in the past decade that developments in instrumental techniques have allowed the extensive analytical application, particularly in the two former fields, where electronic detection can replace photographic methods. Commercially produced instruments are now available on which a sample can be spectroscopically analysed on a routine basis for some twenty to thirty elements.

The talk given by Mr. J. F. Duke (National Physical Laboratory, Teddington) on "Mass Spectroscopy" showed how a double focusing mass spectrometer fitted with a vacuum spark source could be used to detect impurities at, and below, the part-per-million level. The small sample size ( $\mu \mathrm{g})$ and the possibility of detecting upwards of seventy elements in a single analysis offset the high cost of equipment. Future possibilities of the method were discussed. In contrast to some of the more industrial developments for automated and repetitive analysis, Mr. J. S. Forbes (London Assay Office) gave an account of the application of emission spectroscopic methods to : (a) determine impurities in fine gold and silver (and incidentally show the changes in alloy and impurity elements in silver over the past fow centuries); (b) aid in the examination of antique silver articles for detection of fakes; (c) develop possible methods to establish assay standards for platinum.

Mr. J. F. Gidley (Imperial Metal Industries (Kynoch) Ltd., Birmingham) showed how copper alloy production could be controlled at the casting stage by rapid X-ray fluorescence analysis for copper, the alloying constituents and impurities. After suitable preparation the cast sample was examined for fluorescent radiation characteristic of copper, chromium, maganese, iron, nickel, zinc, arsenic and tin. The interpretation of the alloying constituents was straightforward, but content determinations of copper required compensation for the interference effects. Comparison of chemical and routine X-ray results showed an accuracy of 0.20 per cent copper and the accuracy of the constituents was sufficient for control purposes. Results and recommendations for additions to the melt could be reported back in about 5 min. Further developments were required before miscellaneous samples can be adequately analysed. Mr. K. M. Bills (International Nickel Company (Mond), Ltd., Birmingham) described how this analysis technique could be applied to the work of an analytical section dealing with alloy development work involving various sample forms. Both in the talks and discussion, such advantages as the nondestructive nature of the test and the disadvantage of inter-element effect were stressed. The relative merits of X-ray and optical emission methods formed one of the more interesting parts of the symposium.

The extended use of direct-reading spectroscopic instruments in a steel works was described by Mr. L. Gwilliam (Steel Co. of Wales). Samples from the furnace, after some preliminary treatment, were spectroscopically examined for carbon, sulphur, manganese, nickel, copper, tin and phosphorus, and results could be reported by in between 3 and $8 \mathrm{~min}$ with some fifty-seventy samples being handled in an 8-h shift. Development work was being carried out to extend these automatic methods to the analysis of iron and steel-making slags. Eventually, it was hoped to replace much of the present routine chemical analysis on refractory materials and slags by spectrographic and X-ray fluorescence methods.

Mr. C. Frith (Brown Bayley Steels, Ltd.) described how contro] analysis of silicon, manganese, chromium, nickel, molybdenum, copper, niobium, titanium and vanadium for stainless steel production was carried out using direct reading spectroscopic instruments. Attention to calibration procedures and suitable means of applying corrections enabled satisfactory results to be consistently obtained. Out of four thousand analyses of various types of stainless steels made in the past three years only three involved errors which arose from the direct reading method.

Similar applications were found in other metallurgical industries. Some of these were noted by Mr. D. Jukes (Henry Wiggin and Co., Ltd., Heroford) in his description of "Spectrographic Control of Nickel Alloy Production". He emphasized that success in application of direct reading methods depended on meticulous attention to standards and calibration procedure. X-ray fluorescence methods for the determination of major alloying constituents such as chromium, cobalt and molybdenum were adopted and up to 400 determinations of a single element could be made by this method in an 8-h period. Although production analysis will in future place less emphasis on conventional chemical methods, the analytical chemist will be increasingly concerned with the provision of reliable standards.

Both in these papers and the discussion which arose, sample preparation and uniformity of procedure was shown to be extremely important for consistent results. One aspect of this was described in the paper by J. R. Brown and D. Wilkinson (Guest, Keen and Nettlefolds Group Research Laboratory, Wolverhampton) on "The Analysis of High Silicon Steels with a Vacuum Spectrometer". The presence of polythene tubing in the argon circuit (used to 
flush the spark chamber of a direct reading instrument) increased the impurity-levels of oxygen and water vapour in the gas and this contamination could cause erroneous results in the analysis of steels containing more than 1 per cent of silicon. Replacement by copper tubing and purification of the argon over heated magnesium reduced impurity-levels to 7 and 1 parts per million of water vapour and oxygen respectively, and these levels allowed satisfactory analyses for carbon, silicon, phosphorus, manganese and tin in the steels.

The chairmen during the symposium-E. H. S. van Someren (British Welding Research Association),
F. R. Bareham (Aluminium Laboratories, Ltd.), H. T. Shirley (Brown-Firth Research Laboratory) and W. Ramsden (Applied Research Laboratories)successfully supervised the discussion which arose after the papers. Both the comments made then and at more informal sessions showed the values of such a gathering as a means of exchanging information on common problems, but some disappointment was expressed that very few of the more junior analysts were present to profit from hearing the various points of view. It is expected that the papers and comments will be published by Hilger and Watts later this year.
L. Bovey

\section{THE ONTARIO RESEARCH FOUNDATION}

\begin{abstract}
$\mathrm{T}$ HE annual report for 1961 of the Ontario Research Foundation* includes the reports of the director, Dr. A. D. Misener, and the director of research, Dr. A. E. R. Westman, together with the accounts, lists of scientific and technical papers published in 1961 and of professional and technical staff. Dr. Misener claims that in all categories the growth of research and development in Canada is substantial and compares favourably with the rate of growth in the United States and the United Kingdom. During 1956-58, that financed by industry itself in Canada increased by about 20 per cent per annum; in the same period the Foundation's contract research for industry increased by 22 per cent per annum, but research expenditure by both Government and industry is low by a factor of 3-4 when expressed as a percentage of the gross national product, and in research performed by industry but financed by Government is low by a factor of 11 compared with the United Kingdom and 19 compared with the United States.

Dr. Westman notes an overall expansion in sponsored research in 1961, particularly in chemistry, a reduction in science activities, particularly in engineөring and metallurgy, and difficulties in recruiting junior staff. The Department of Biochemistry

- Ontario Research Foundation. Annual Report, 1961. Pp. 64. (Toronto: Ontario Research Foundation, 1962.)
\end{abstract}

concluded a study of the effect on the serum cholesterol-level in rats of a diet containing hydrogenated sunflower oil, but a new investigation was commenced on the effect of agitation on the isomeric fatty acids produced in hydrogenation. Basic research was continued in the Department of Chemistry on the study of stereo-specific catalysts for polymerization and the mechanism of the polymerization of butene by the hoterogeneous catalyst aluminium triisobutyltitanium trichloride, as well as work on phosphate glasses, while in physical metallurgy, unsponsored research included studies in metal physics, the magnetic properties of iron ore and copper alloy surfaces. The Department of Parasitology completed a study of the throat bots of deer and established the mode of transmission of 'brain worms' of deer with certain land snails as intermediate hosts. A survey of fish parasites in lakes was extended, and a new study on a warble fly, the larvæ of which live under the skin of certain wild animals, showed that the activity of the animal is reduced if it harbours many of these parasites, which may cause death directly or make the animal unable to escape predators. The Department of Physiography made further examination of the Algonquin Lake plain, and in the Department of Textiles unsponsored research was concerned with the chemical modification of cotton cellulose, wool and hair to give improved fabrics.

\section{ENGINEERING DEVELOPMENTS IN THE BRITISH BROADCASTING CORPORATION}

$\mathrm{T}$ HE excellent series of monographs describing the work of the Engineering Division of the British Broadcasting Corporation (Nature, 191, 1355; 1961), has been supplemented by five further issues* since September 1961.

As their titles indicate, these monographs deal with a range of subjects from basic research in the

* B.B.C. Engineering Monograph No. 38: “Operational Research on Microphone and Studio "Techniques in Stereophony", D. E. L. Shorter. Pp. 23. No. 39: "Twenty-five Years of B.B.C. Television" Sir Harold Bishop. Pp. 41. No. 40: "The Broadcasting of Musie in Television". Part I, Introdnction, R. F. A. Pottinger. Part II, Sound and Vision, L. Salter. Part III, Operational Technique, E. G. M. Alkin. Part IV, Acoustic Treatment of Television Studios, C. L. S. Gilford, pp. 23. No. 41: "The Design of a Group of Plug-in Television Studio Ampliflers", K. J. Austin, Pp. 19. No. 42: "Apparatus for Television and sound Relay Stations", F.A. Peachey, R. Toombs and D. L. Smart 58. eacil.) techniques necessary for a high-quality broadcasting service, to the actual design and development of the equipment installed at the steadily increasing number of transmitting stations in Britain.

In Monograph No. 39, the director of engineering, B.B.C., Sir Harold Bishop, presents a comprehensive review of the development of the television service in Britain, starting with a reminder of the early history of the subject, thus: "Although all the funda. mentals of an electronic transmitting and receiving system were put forward by A. A. Campbell-Swinton in his famous letter to Nature as far back as June 1908 [Vol. 78, 151], no practical realization of his proposals was attempted until the early 'thirties'.

The earliest B.B.C. television transmissions started in 1926 when pictures from John Logie Baird's 